\title{
Problem solving and creativity in Engineering: turning novices into professionals
}

\author{
Jonathan Adams, University of Northampton, Stefan Kaczmarczyk, University of \\ Northampton, Philip Picton, University of Northampton and Peter Demian, Loughborough \\ University
}

\begin{abstract}
Recent UK and European benchmarks for both undergraduate and professional engineers highlight the importance of problem solving skills. They additionally identify creativity as an important capacity alongside problem solving for both novices and professionals. But, how can we develop and encourage these important skills in undergraduate engineers?
\end{abstract}

For many years researchers have explored how the differences between novices and experts might show educators techniques for improving the problem solving abilities of their students. Whilst it is often appreciated that knowledge and experience have a large influence on problem solving ability, it is not feasible to develop these fully in a three or four year degree course. There are, however, a number of other capacities relating to problem solving process skills that can be usefully developed, such as strategy, attitude and motivation.

A number of semi-structured interviews have been undertaken with engineering undergraduates at The University of Northampton, Loughborough University and Birmingham University in order to explore these issues. Analysis has been in the form of a phenomenographic study. The interviews extend their questioning and comparison beyond problem solving skills into creative thinking.

This paper provides a brief summary of previous published research alongside interesting findings from the interviews. Early findings have been used to inform an action research project to develop a problem-based learning (PBL) module to improve creative problem solving skills in undergraduate engineers. Emerging themes that have been identified include: identification of problem solving processes in the case of professionals as opposed to simply identifying skills required in the case of students, confusion with the concept of 'creativity' in the context of engineering; issues with motivation and ownership with regard to academic problems and significance being placed on real life activities involving groupwork as an effective way of teaching and learning creative problem solving.

\section{Key Words: Engineering Education, Problem Solving, Creativity, Interviews, Professional, Novice, Phenomenography}

\section{Introduction}

The ability to solve problems and creative potential are highlighted as essential characteristics for both novice undergraduate engineers and qualified engineering professionals in UK benchmark statements (Engineering-Council-UK, 2005, QAA, 2006):

"The creative way of approaching all engineering challenges is being seen increasingly as a 'way of thinking' which is generic across all disciplines. [...] 
They [engineering undergraduates] will want to solve problems and have strategies for being creative, innovative and overcoming difficulties by employing their knowledge in a flexible manner." (QAA, 2006).

Creativity within the sciences, including engineering, is also identified, both explicitly and implicitly as an important driver in recent UK reviews relating to economic prosperity and Government science and innovation policies (Leitch, 2006, Sainsbury, 2007).

In Europe, problem solving and creativity are presented as important competencies in the requirements for European Engineer (Eur. Ing.) designation (FEANI, 2000).

"Engineers aware of their professional responsibilities should strive to achieve competence such as [...] an ability to apply theoretical and practical methods to the analysis and solution of engineering problems [...] an awareness of continuous technical change and the cultivation of an attitude to seek innovation and creativity within the engineering profession" (FEANI, 2000).

What these statements fail to do, however, is to offer guidance on how problem solving and creativity might be fostered and taught, let alone how they might be assessed.

It is against a backdrop of benchmark statements and policies that educators must devise and implement strategies for developing, enhancing and assessing creativity and problems solving skills within the sciences and engineering.

Strategies for teaching problem solving and for the development of creativity can be found in many texts, and in numerous research publications (Woods, 1977, Felder, 1998, Dewulf and Baillie, 1999, Felder, 2006). It is possible to identify, from both anecdotal sources and more defined evidence that deficiencies continue to exist in the teaching of creative problem solving skills, and that the traditional model of teaching used in engineering education may not provide sufficient motivation for engineering undergraduates (Felder, 2006). Wankat and Oreovicz (1992) suggest, however, that while engineering education focuses heavily on problem solving skills, lecturers and professors continue to concentrate on teaching content rather than showing the processes involved in problem solving. Houghton (2004) proposes that problem solving is 'what engineers do'. He contends that problem-solving skills may be the most important thing we can teach our students.

Valuable research also exists on the characteristic differences between expert and novice problem solvers, and how this can help our understanding of developing problem solving skills in the classroom (Selden and Selden, 1997, Breslow, 2001).

It is clear that deficiencies continue to exist in the teaching of problem solving process skills, and particularly with the development and assessment of creativity within engineering. This study attempts to identify current perceptions and characteristics of both novice and professional engineers through a series of open-ended interviews. By comparison of these current perceptions it is anticipated that emerging themes can be used to inform effective instruction to develop these skills with engineering students.

Fifty-three semi-structured interviews have been conducted over a two year period as an extension to an action research project involving engineering undergraduates at The University of Northampton (Adams et al., 2007, Adams et al., 2008). The interviews with 
novice undergraduates are further supported by interviews with practicing professional engineers and engineering academics. The interviews have been conducted at The University of Northampton, Loughborough University and Birmingham University.

This paper begins with a summary of previous research into the differences between novice and expert problem solvers. Alongside this, findings from an initial twenty-five interviews undertaken with professional engineers and students and academics at The University of Northampton are considered. Work is currently underway to provide a comprehensive analysis of all fifty-three interviews. As an extension to previous studies the interviews in this work extend their questioning and comparison beyond problem solving skills into the perceptions of creativity within engineering. The concept of creativity in engineering is currently topical.

\section{Experts and Novices}

There are reportedly a number of characteristics that differentiate an expert from a novice problem solver. These include the use of memory, attitude, strategy and visualisation (Wankat and Oreovicz, 1992). Perhaps central to this difference is how experts and novices initially think about problems. Experts tend to examine the problem as a whole before moving to a physical representation of it. Only then do they employ formulae and equations to solve it. Novices have a tendency to jump straight in (Breslow, 2001).

Defining the terms "problem type" and "expert" offers us more challenges. A problem could be a routine text book exercise or a complex mathematical task. Similarly, an expert may be someone who knows the domain thoroughly and can solve problems in an automatic manner, or someone who can abstract process skills and utilise these in solving non-routine problems. Whilst experts often possess extensive knowledge, it is the latter that are more successful in solving unfamiliar problems.

Studies carried out by cognitive psychologists such as Larkin and Simon (Larkin et al., 1980a, Larkin et al., 1980b, Larkin et al., 1980c, Larkin, 1983) in the 1980s often employed text book exercises that physics novices and experts had to solve. Their studies observed and identified behaviour whilst solving the problems, and made suggestions for improvements in instruction. Typical findings were that experts tended to "work forwards" looking at the givens of the problem first and moving from the problem statement to a physical representation of it. Only after this analysis did they apply equations and formulae. Novices were observed to employ a "working backwards" approach trying to find what procedure would get them to the answer. They tended to adopt a more 'trial and error' approach; memorising and applying equations independent of context or relationship to the problem.

Similar studies with engineering students confirm these earlier findings with physics students (Greenfield, 1979, Greenfield, 1987). Students who were successful were able to apply specific pieces of knowledge in order to solve problems. Unsuccessful students were unable to relate what they had learnt to problems that were of a non-familiar nature.

These studies were performed at a micro level; observing process whilst solving often welldefined problems of a mathematical nature. They nevertheless highlight and reinforce the importance of teaching and developing process skills involved with problem solving, such as those in Pounds' (1969) eight-step model (select a problem, consider alternative solutions, evaluate solutions, select a solution, execute solution, chose a model or goal, compare it with 
reality, identify differences) or Woods' (1977) five-step model: (define the problem, think about it, plan, carry out the plan, look back).

Unlike problem solving, creativity as a concept is rather more difficult to define or understand. There are numerous definitions of creativity, many of which offer little to our understanding of how it might be taught, let alone assessed.

In a detailed study of creativity, Dewulf and Baillie (1999) explore a range of definitions, finally arriving at a working definition as: "Creativity is shared imagination". In this definition 'imagination' is further defined as novel (rather than visual) memory and individual or personal and 'shared' in a sense of being able to communicate these ideas with others so that they can reconstruct this imagination. They deduce through their research and by way of several case studies across arts, science and engineering that creativity as a concept is a multidisciplinary or perhaps 'non-disciplinary' subject that applies equally to any discipline. Through case studies involving industry they further explore the tensions of creativity versus innovation (and invention), which are perhaps more widely accepted concepts within engineering:

"Once a creative idea finds route to commercialisation i.e. an application within a market, it becomes an innovation. If the creative idea is not domain-specific it becomes an invention" (Dewulf and Baillie, 1999).

It is perhaps the commonplace use in engineering of the terms innovation (through entrepreneurship) or invention to mean creativity that differentiate it from other disciplines such as art or music. These are the tangible results of the creative process and are not the creative process itself. Similar conclusions were reached by a multi-disciplinary think-tank event hosted by the Higher Education Academy Engineering Subject Centre, thereby indicating a clear need to address the issues of creativity in engineering.

Attributes related to creativity which might be considered to differentiate novices from experts include: knowledge (Weisberg, 1999), intelligence (Sternberg, 1997), motivation/enthusiasm (Abra, 1997), memory (Gelb, 1996), environment (Abra, 1997) and communication (Bohm, 2004). Other attributes are thinking skills (convergent and divergent), creative techniques, personal and group work, freedom to experiment and reflection.

In order to confirm and investigate issues identified in previous studies, and to explore more fully the concept of creativity in engineering the approach adopted in this study is at a macro level; seeking perceptions and views of novices and experts through a series of interviews rather than by analysis of solving a particular problem in practice.

\section{Interview Process and analysis}

Fifty-three semi-structured interviews in total have been carried out with engineering undergraduates, academics and professional engineers although this paper only considers an initial twenty-five. The purpose of the interviews was to investigate characteristic similarities and differences between expert and novice problem solvers in engineering, and how this might inform the development of problem solving skills and creative thinking in a dedicated problem-based learning (PBL) module with undergraduate engineers. The interviews asked three open-ended questions: "what qualities do you think make a good problem solver?", 
"what do you understand by 'creativity' in relationship to engineering?", and "how do you think that these skills can be improved in undergraduate engineers?"

The interviews have been digitally recorded, and transcribed for analysis. Overall length of audio data for all interviews is approximately 30 hours, and 15 hours for the initial twentyfive interviews considered here. Whilst detailed analysis is still in progress, this is in the form of a phenomenographic study (Marton, 1981, Kvale, 1996, Sandberg, 1997, Vincent and Warren, 2001).

Phenomenography is a research technique developed by Ference Marton in the late 1980's (Marton, 1981, Marton, 1988) that can be used to investigate the qualitative differences of how people think or perceive something. Phenomenographic data is collected through a series of open-ended interviews, which are then transcribed and analysed through iterative readings to produce an 'outcome space' (Dortins, 2002). The 'outcome space' represents an ordered set of related categories of the concept being studied.

The method through which the interviews are obtained, and transcripts produced are of particular importance to the research process in order to avoid bias, misinterpretation or loss of data (Kvale, 1996). Interpretative awareness relies on a technique termed 'bracketing' whereby the researcher brackets or suppresses their own preconceived ideas whilst performing interviews, or analysing transcripts (Sandberg, 1997, Ashworth and Lucas, 2000).

The results presented below represent an analysis of the initial twenty-five interviews and transcripts, alongside a selection of direct quotations. Early indication is that the remainder of interviews undertaken at other universities tends to support these initial findings.

\section{Findings and analysis}

Tabulated results presented here relate to the three interview questions asked and are grouped into related response categories from students, academics and professionals. Some ordering of importance is present within each of the category lists in order to form an 'outcome space' of responses. Direct quotations are identified with S, A or P denoting student, academic or professional respectively. A more detailed analysis of transcripts and recordings is currently being undertaken and so only some of the initial key findings are presented here. 


\section{Q1: WHAT QUALITIES DO YOU THINK MAKE A GOOD ENGINEERING PROBLEM SOLVER?}

TABLE 1 SUMMARY FOR QUESTION 1

\begin{tabular}{|c|c|c|}
\hline Student & Academic & Professional \\
\hline $\begin{array}{c}\text { Analysis of question } \\
\text { Practice } \\
\text { Analytical skills } \\
\text { Variability in terms of ownership } \\
\text { Motivation: grades, learning, } \\
\text { career } \\
\text { Maths skills } \\
\text { English skills } \\
\text { Consulting with others } \\
\text { Looking from other viewpoints } \\
\text { Communication } \\
\text { Priorities and Focus }\end{array}$ & $\begin{array}{c}\text { Experience and Practice } \\
\text { Trial and Error } \\
\text { Prior knowledge } \\
\text { Reflection } \\
\text { Sorting information; synthesis } \\
\text { Good understanding of what to } \\
\text { be achieved } \\
\text { Skills and not content or } \\
\text { knowledge }\end{array}$ & $\begin{array}{c}\text { Naturally enquiring mind } \\
\text { Motivation to make things } \\
\text { better } \\
\text { Asking questions and asking } \\
\text { others } \\
\text { Scoping of problems } \\
\text { Recognizing what you do and } \\
\text { don't know } \\
\text { Flexibility in method } \\
\text { Reflection on method and } \\
\text { having other strategies } \\
\text { Thinking in different ways } \\
\text { (pictures) } \\
\text { Questioning and listening } \\
\text { Making things basic/simple } \\
\text { Thinking skills } \\
\text { Logic skills/process skills } \\
\text { Analysis and application of } \\
\text { analysis } \\
\text { Risk taking }\end{array}$ \\
\hline
\end{tabular}

An analysis of responses to Question 1 is shown in Table 1. In the interviews both professionals and academics identify explicitly the need to have a process or strategy when solving problems. The explicit identification of a problem solving process was not evident in student interviews. This suggests a need for developing awareness of thinking about the process of problem solving (metacognitive processes) in students, which indeed reinforces the basis for this study.

P: "Flexibility in method is important; if plan A doesn't work then diagnose your approach; you need the ability to step back and see objectively what you are doing."

A: "Students don't reflect the way I see it; people tend to concentrate on teaching content rather than key skills."

It was also evident from the interviews that students tended to be focused on analysing/understanding the problem and identifying skills (which they might already have) to assist with working a solution (a working backwards approach). Where a knowledge or skills deficit was encountered then research (meaning finding information) and 'talking it over' was offered as a potential way of overcoming this. Professional engineers on the other hand demonstrated a broader outlook by considering the task as a whole while selecting and adapting strategies which include both skills and method (a working forwards approach). Their strategy also called on external expert help when required by talking to colleagues and 
professional networks. Interestingly these notions of research and talking problems over were not so evident in academics. These findings support those of Larkin and Simon (Larkin et al., 1980a, Larkin et al., 1980b, Larkin et al., 1980c, Larkin, 1983) which have been reported previously.

Whilst intrinsic motivation (being personally interested in a task or problem) was perceived in the interviews as probably the most important concept, reward is rated more highly by students and academics in contrast to the desire to make things better by professionals. Reward is related to grade or employment opportunities by both students and academics. The influence of both motivation (intrinsic and extrinsic) and reward on creativity and problem solving is well documented within the literature (Polya, 1957, Peters, 1960, Sternberg, 1991, Abra, 1997).

S: "Motivation is wanting to learn and end grade."

A: "Motivation is a two way thing; you need to challenge and motivate students."

P: "Motivation is important into making things better than they already are."

Another perception that became apparent during interviews with students was that of ownership of academic problems. Taking responsibility (or ownership) of a problem has potential implications for motivation. In the interviews over $50 \%$ of students interviewed believed that some academic problems clearly belonged to the problem setter (the tutor). This observation is interesting, and has possible implications with a student's motivation to perform well when undertaking academic problems.

S: "I don't own the problem as I have not dreamt it up."

S: "Ownership of the academic problem is clearly with the problem setter."

Findings from this question suggest the need to devise instruction and activities which develop awareness of problem solving processes. They also suggest other useful activities would be developing effective research (information finding) skills, and encouraging and enabling discussions (networking) whilst problem solving. These should be facilitated during the early part of an engineering student's studies, which is not necessarily always the case at present. 


\section{Q2: WHAT DO YOU UNDERSTAND BY 'CREATIVITY' IN RELATIONSHIP TO ENGINEERING?}

TABLE 2 SUMmary FOR QUESTION 2

\begin{tabular}{|c|c|c|}
\hline Student & Academic & Professional \\
\hline Natural thing & Product design - you mean & Making things better \\
\hline Visual, product design, & Rolatecto manufacture & Innovation \\
\hline musician, artist & $\begin{array}{l}\text { Relates to manufacture, } \\
\text { architecture, design }\end{array}$ & You are or are not creative \\
\hline box" & $\begin{array}{c}\text { Easier to see in artist or } \\
\text { musician }\end{array}$ & $\begin{array}{c}\text { Born with it, but can be } \\
\text { improved }\end{array}$ \\
\hline Knowledge & Problems with word "creative" & Questioning \\
\hline $\begin{array}{l}\text { Intuition } \\
\text { Links to logic }\end{array}$ & Design flair and knowledge & $\begin{array}{l}\text { Doing something that a } \\
\text { computer can't do }\end{array}$ \\
\hline $\begin{array}{l}\text { Objective not subjective in } \\
\text { engineering (it has to work) }\end{array}$ & $\begin{array}{l}\text { Merging of disciplines } \\
\text { Techniques like brainstorming }\end{array}$ & $\begin{array}{c}\text { Solution that is not out of a } \\
\text { book }\end{array}$ \\
\hline $\begin{array}{l}\text { Direction without being given } \\
\text { Something new }\end{array}$ & People who work outside in & $\begin{array}{l}\text { Close to devious (in terms of } \\
\text { patents) }\end{array}$ \\
\hline Different perspectives & against criteria & Moving away from the norm \\
\hline Brilliant ideas & Relates to logic & Requires correct environment \\
\hline Not black and white & Challenged to think & Increases under pressure \\
\hline
\end{tabular}

Analysis of responses to Question 2 is shown in Table 2. There are two key themes that are dominant for this question; the lack of agreement as to a definition of what creativity is within engineering, and the perception of creativity as a personal capacity which not every individual might possess.

Discussions during the interviews clearly indicate some stigma with the notion of creativity within an engineering context. Whilst many interviewees saw a place for creativity within engineering, there was no real agreement as to what this was and as to whether it was a capacity that everyone possessed or that could be developed. These perceptions have implications for developing and encouraging this skill in both engineering student and professional engineers, even though it is clearly specified in benchmark statements. It is perhaps these negative perceptions that need to be overcome. Alternatives like 'ingenuity' and 'innovation' were often seen as more appropriate to engineering.

S: "Creativity is quite tough to define as an engineer; is it design problems?"

A: "It's what the product designers do, you're getting it confused with ingenuity; creativity will sell a product, but ingenuity will find a new way of manufacturing it."

P: "A solution that is not blindingly obvious to someone with similar skills and experience; I think I have given you a definition of innovation; the novel step."

There appeared also to be some general agreement that creativity in engineering meant devising a process or solution that does not follow conventional methods. A dominant concept for professional engineers was creativity involving improvement as opposed to producing something new. This notion was clearly related to market advantage, and was also 
suggested as a means of overcoming patent restrictions. The importance of having a motivating environment which encouraged creative thinking was also highlighted.

S: "Creativity is thinking of something new."

A: "I suppose it is a mixture of design flair and engineering knowledge; creativity is the merging of several disciplines; form, fabric and function all merges."

P: "Creativity is part of making things better still; if you have not got a creative outlook then you are doing something by hand that a computer can do."

Many respondents also believed that creativity, like having musical ability, was something that was internalized although it was also speculated that it could be improved or enhanced.

Findings from the interviews correspond with a number of factors which are highlighted within the literature such as creativity involving personality, environment and motivation (Abra, 1997).

It is perhaps these perceptions of creativity involving improvement and requiring a motivating environment that offer mechanisms for developing creative thinking skills in undergraduate engineers. There is also a need to overcome any preconceived perception of 'creativity' within engineering involving aesthetically pleasing artefacts and with the notion of creativity being a personal capacity that cannot be developed. 


\section{Q3: HOW DO YOU THINK THAT THESE SKILLS CAN BE IMPROVED IN UNDERGRADUATE ENGINEERS?}

TABLE 3 SUMmARY FOR QUeSTION 3

\begin{tabular}{|c|c|c|}
\hline Student & Academic & Professional \\
\hline $\begin{array}{c}\text { Practical work } \\
\text { Group work } \\
\text { Technical work } \\
\text { Business skills (presentation } \\
\text { and reports) } \\
\text { Clear links between theory and } \\
\text { practice } \\
\text { Competitive tasks } \\
\text { Free time for exploration and } \\
\text { research } \\
\text { Interaction } \\
\text { Profiling of students / } \\
\text { differential teaching }\end{array}$ & $\begin{array}{c}\text { Reflective tasks } \\
\text { More practice } \\
\text { Practical work, but simple } \\
\text { Communication skills } \\
\text { Group work } \\
\text { Problems with multiple } \\
\text { solutions } \\
\text { Mini projects } \\
\text { Constraints to take out of usual } \\
\text { methods (adaptation of } \\
\text { problems) } \\
\text { Placing values on skills } \\
\text { developed } \\
\text { Explain benefits to them / } \\
\text { articulation of skills being } \\
\text { developed }\end{array}$ & $\begin{array}{c}\text { Communication skills } \\
\text { Practical work within abilities } \\
\text { Developing questioning } \\
\text { Thinking and questioning skills } \\
\text { Thought processes } \\
\text { Adding of process skills to } \\
\text { assignments - reflection } \\
\text { Developing process skills } \\
\text { Giving surprises or adaptations } \\
\text { Being challenging, ambitious } \\
\text { problems } \\
\text { Techniques (e.g. } \\
\text { etc.) } \\
\text { brainstorming, logical approach } \\
\text { Group decision work / } \\
\text { Teamwork } \\
\text { Real world problems / } \\
\text { motivational } \\
\text { Environment to develop and } \\
\text { hone skills } \\
\text { Study groups } \\
\text { Case studies and briefs }\end{array}$ \\
\hline
\end{tabular}

Analysis of responses to Question 3 is shown in Table 3. Two key themes that emerge from this question are the demand for practical, real life activities alongside the opportunity to undertake groupwork. Professional engineers additionally identify the need for challenges and the value of having a motivating environment. These findings agree with those of Felder (1998) who proposes the use of effective PBL exercises within a suitable environment to develop creative problem solving skills for engineering students.

S: "Let us try more practical things; solving of equations is just maths, you need to relate this to practical things."

A: "They don't have hands-on experience; they have not built things and failed."

P: "Give student's real problem to solve not just routine calcs; put them in an environment where they can demonstrate skills and hone the skills that they already have."

Communications skills and group and team work are identified by each group as another important element. 
S: "Group work brings out skills in individuals in others that they cannot express when working individually."

A: "Communication is useful for a whole range of jobs; students need to see value in the skills that are not being tested."

P: "Spelling and communication skills- presentation is all; in industry there is not always a next time."

The findings show importance being placed on developing analysis, synthesis, reflection and communication skills, with professional engineers identifying and rating these abilities more highly than engineering students. The setting of realistic problems which introduce challenge, surprises or adaptations are also highlighted by professionals as being useful.

S: "There needs to be incentives to do things that are not part of the core."

A: "Students need to be far more switched on; they need to reflect and question things."

P: "I don't want yes people, they must be able to think and question. They must be able to handle surprises and more than one thing at a time; at the end of the day you need to be ambitious."

It is interesting to note that the key concepts identified as important for effective problem solving in Question 1 were not rated as significant factors when considering ways of improving problem solving skills in engineering undergraduates. These include research (fact finding) skills, 'talking problems over' and developing problem solving processes or strategies. It might be implied that these are developed through the use of challenging real life problems involving groupwork.

\section{Conclusions and further work}

Preliminary analysis of interviews and transcripts highlights a number of interesting points which largely agree with previous studies, although a number of additional issues are identified. It must be noted that the research techniques used in this work are quite different from previous studies; open-ended interviews as compared with prescriptive observation of solving a mathematical problem.

Findings from Question 1 confirm previous studies in that students tended to identify discrete skills appropriate to stages of a typical problem solving process rather than taking a holistic process-based approach. Students also tended to concentrate on analysing the problem and identifying what knowledge or skills they already had. Professionals on the other hand took a broader approach by considering the problem as a whole and selecting and adapting strategies accordingly. This clearly shows the need to develop activities and instruction that develop process skills. It was also apparent that when a knowledge deficit was encountered in both students and professionals that an attempt was made to resolve this through research (information finding) or talking to other people. What is being observed here is the notion of knowledge networking, as suggested by Allen and Long (2009). In order for students to apply knowledge acquired this way effectively requires additional skills such as criticality, reasoning, synthesis and presentation. These skills are often not developed until much later 
in undergraduate studies (towards their dissertation), so suggesting perhaps these should be developed much sooner.

Further perceptions that became apparent during the interviews relate to motivation involving reward, and to the notion of motivation through ownership. Many students and some academics cited reward as being the key motivator for attempting to achieve well at solving academic problems. This reward was predominantly academic assessment grades, or enhanced employment opportunities. Connected to this was the notion, by a large proportion of students, that they were undertaking tasks or solving problems for someone else, and that motivation through taking ownership was subsequently low. Both of these perceptions relating to motivation might be considered as detrimental to developing effective skills in undergraduates. It is these factors that need consideration in developing effective and motivating instruction.

In Question 2, looking at the perceptions of what creativity is in engineering, themes are largely convergent across students, academics and professionals, but with some exceptions. Two key perceptions relate to the actual use of the word creative within an engineering context, and with the belief that being creative is a personal capacity. Whilst it was not disagreed that there was a place for creativity within engineering, this was often associated with artistic subjects such as music or art than with engineering. Other associated, but probably more tangible concepts such as innovation, ingenuity and entrepreneurship were offered in many cases as more suitable alternatives. It was also widely believed that creativity (and its associated concepts) was a personal, internalised capacity that not every person might be able to demonstrate or call upon. In nearly all cases, creativity was associated with some end product or artefact, and seldom with the process that had been undergone to come to a conclusion. Creativity as a process of improvement, as opposed to devising something new, was the most important perception for the professional engineer. It is, perhaps, these preconceived perceptions that need to be overcome when raising the profile of creativity with engineering students, and in the engineering arena as a whole.

Question 3 asks for perceptions of what might be done in order to improve problem solving skills and encourage creative thinking in engineering undergraduates. Again, responses from both novices and professionals were agreeable and predictable in that both practical activities and the involvement of groupwork (or teamwork) were perceived as essential commodities for improving these skills. Whilst a whole range of practical activities were identified, ranging from project work and design tasks to case studies and industrial placements, the emphasis here was clearly on their applicability to real life. In addition, professional engineers identify the requirement for a stimulating and motivating environment. Indeed, it is both suitable practical activities involving groupwork and environment that have been taken forward into the activities within the action research extension of this study.

Work continues with the analysis of interviews and transcripts in order to provide a more detailed study. A number of further interviews have already been conducted at Loughborough University and Birmingham University, and the interviewing process is now complete. Due to the amount and richness of the data, further analysis is being undertaken in the qualitative research software Nvivo.

Early results from this research have already been used to inform the planning, delivery and curriculum of an action research project in which a dedicated problem-solving and creative 
thinking problem-based learning (PBL) module for undergraduate engineers has been devised.

\section{References}

Abra, J., (1997) The Motives for Creative Work, Creskill, NJ: Hampton Press

Adams, J., Kaczmarczyk, S., Picton, P. \& Demian, P., (2007) Improving Problem Solving and Encouraging Creativity in Engineering Undergraduates, International Conference on Engineering Education ICEE 2007, Coimbra, Portugal.

Adams, J., Turner, S., Kaczmarczyk, S., Picton, P. \& Demian, P., (2008) Problem Solving and Creativity for Undergraduate Engineers: findings of an action research project involving robots International Conference on Engineering Education ICEE 2008, Budapest, Hungary.

Allen, M. \& Long, J., (2009) Learning as Knowledge Networking: Conceptual Foundations for Revised Uses of the Internet in Higher Education International Conference on Education and Information Technology 2009, San Francisco, USA.

Ashworth, P. \& Lucas, U., (2000). Achieving Empathy and Engagement: a practical approach to the design, conduct and reporting of phenomenographic research. Studies in Higher Education, 25 (3), 295 - 308.

Bohm, D., (2004) On Creativity, Oxfordshire: Routledge.

Breslow,L., (2001) Transforming Novice Problem Solvers into Experts [online]. http://web.mit.edu/tll/tll-library/teach-talk/transforming-novice.html [Accessed November 2008].

Dewulf, S. \& Baillie, C., (1999) CASE Creativity in Art, Science and Engineering - How to foster Creativity UK: Department for Education and Employment.

Dortins, E., (2002) Reflections on phenomenographic process: Interview, transcription and analysis 2002 Annual International Conference of the Higher Education Research and Development Society of Australasia, Perth, Australia: Higher Education Research and Development Society of Australasia, 207 - 213.

Engineering-Council-UK, (2005) Chartered Engineer and Incorporated Engineer Standard: Engineering Council UK.

FEANI, (2000) Guide to the FEANI Register: Eur Ing. Federeation Europeenne D'Associations Natioanles D'Ingenieurs.

Felder, R., (1998) Creativity in Engineering Education. Chemical Engineering Education, 22 (3), 120-125.

Felder, R., (2006) Teaching Engineering in the 21st Century with a 12th Century Teaching Model: How Bright is that? Chemical Engineering Education, 40 (2), 110-113.

Gelb, M., (1996) Putting your creative genius to work: How to sharpen and intensify your mind power, Illinois: Nightingale Conant. 
Greenfield, L., (1979) Engineering Student Problem Solving. In J. Lockhead \& J. Clements (eds.) Cognitive Process Instruction. Pensylvania: The Franklin Institute Press, 229 - 238.

Greenfield, L., (1987) Teaching Thinking through Problem Solving. In J. Stice (ed.) Developing Critical Thinking and Problem Solving Skills. San Francisco: Jossey Bass

Houghton, W., (2004) How can Learning and Teaching Theory assist Engineering Academics? [online]. School of Engineering - University of Exeter. Available from: http://www.engsc.ac.uk/er/theory/problemsolving.asp [Accessed November 2007].

Kvale, S., (1996.) InterViews: an introduction to qualitative research interviewing, California: Sage.

Larkin, J., (1983) The role of problem representation in physics. In D. Gentner \& A. Stevens (eds.) Mental Models. Hillside NJ: Erlbaum.

Larkin, J., Heller, J. \& Greeno, J., (1980a) Instructional Implications of Research on Problem Solving. New Directions for Teaching and Learning, 2, 55 - 57.

Larkin, J., McDermott, J., Simon, D. \& Simon, H., (1980b) Expert and novice performance in solving physics problems. Science, 208, 1335 - 1342.

Larkin, J., McDermott, J., Simon, D. \& Simon, H. (1980c) Models of competence in solving physics problems. Cognitive Science, 4, 317 - 348.

Leitch, (2006) Prosperity for all in the global economy - world class skills. London.

Marton, F., (1981) Phenomenography - Describing Conceptions of The World Around Us. Instructional Science, 10, 177 - 200.

Marton, F., (1988) Phenomenography: Exploring Different Conceptions of Reality. In D. Fetterman (ed.) Qualitative Approaches to Evaluation in Education: The Silent Scientific Revolution. New York: Praeger Publishers, 176 - 205.

Peters, R. (1960) The Concept of Motivation London: Routledge \& Kegan Page.

Polya, G., (1957) How to Solve It: a new mathematical method New York: Doubleday.

Pounds, W., (1969) The Process of Problem Finding. Industrial Management Review, 11, 1 19.

QAA, (2006) Subject Benchmark Statement - Engineering: The Quality Assurance Agency for Higher Education (QAA).

Sainsbury, (2007) The Race to the Top: A Review of Government's Science and Innovation Policies. London.

Sandberg, J., (1997) Are Phenomenographic Results Reliable? Higher Education Research and Development, 16 (2), 203 -212. 
Selden, J. \& Selden, A., (1997) What does it take to be an expert problem solver [online]. The Mathematical Association of America. Available from: http://www.maa.org/t_and_1/sampler/rs_4.html [Accessed January 2008].

Sternberg, R. (1991) Complex Problem Solving: Principles and Mechanisms Hillside, NJ: Lawrence Erlbaum Associates.

Sternberg, R. (1997) The Nature of Creativity: Contemporary psychological perspectives Cambridge: Cambridge University Press.

Vincent, C. \& Warren, S., (2001) This won't take long ...: Interviews, ethics and diversity. Qualitative Studies in Education, 14 (1), 39 - 53.

Wankat, P.C. \& Oreovicz, F.S., (1992) Teaching Engineering [online]. http://dequim.ist.utl.pt/wankat/ [Accessed August 2009].

Weisberg, R. (1999) Creativity and Knowledge: A Challenge to Theories. In R. Sternberg (ed.) Handbook of Creativity. Cambridge: Cambridge University Press.

Woods, D., (1977) On Teaching Problem Solving - Part II: The Challenges. Chemical Engineering Education, Summer 11, 141-144.

\section{About the authors}

Jonathan Adams is head of lift education in the School of Applied Sciences at the University of Northampton.

Email: jonathan.adams@ northampton.ac.uk

Dr Stefan Kaczmarczyk is Senior Lecturer in Engineering in the School of Applied Sciences at the University of Northampton.

Professor Philip Picton is divisional leader in Engineering in the School of Applied Sciences at the University of Northampton.

Dr Peter Demian is a lecturer in Construction Management in the Department of Construction and Building Engineering at Loughborough University. 